\title{
Case Report: Clinical and Diagnostic Aspects of Mayer-Rokitansky-Kuster-Hauser Syndrome
}

\author{
Lucas Ferreira de Paula Filho ${ }^{1 *}$, Guilherme Carolino Neves ${ }^{2}$, Laís Figueira Bandoli², \\ Lucas Caraline de Almeida Coelho², Nathália de Souza Ferreira Feital'2, Renan Vieira Murad², \\ Ana Luísa Conceição de Jesus ${ }^{3}$, Diana Aristótelis de Sá1, Larissa Bianca Cunha de Sá1, \\ Jonathan Mwambire4, Alberto Krayyem Arbex ${ }^{1,4}$
}

\author{
${ }^{1}$ IPEMED Medical School/AFYA Educational, Postgraduation in Endocrinology, Rio de Janeiro, Brazil \\ ${ }^{2}$ UNIFESO Medical School, Teresópolis, Brazil \\ ${ }^{3}$ Department of Pediatrics, Medical School, University of São Paulo (USP), São Paulo, Brazil \\ ${ }^{4}$ Medical Clinic in Endocrinology and Diabetology, Schleswig-Flensburg, Germany \\ Email: *drlucasferreira@yahoo.com.br
}

How to cite this paper: de Paula Filho, L.F., Neves, G.C., Bandoli, L.F., de Almeida Coelho, L.C., de Souza Ferreira Feital, N., Murad, R.V., de Jesus, A.L.C., de Sá, D.A., de Sá, L.B.C., Mwambire, J. and Arbex, A.K. (2019) Case Report: Clinical and Diagnostic Aspects of Mayer-Rokitansky-Kuster-Hauser Syndrome. Health, 11, 1367-1372.

https://doi.org/10.4236/health.2019.1110105

Received: August 25, 2019

Accepted: October 19, 2019

Published: October 22, 2019

Copyright $\odot 2019$ by author(s) and Scientific Research Publishing Inc. This work is licensed under the Creative Commons Attribution International License (CC BY 4.0).

http://creativecommons.org/licenses/by/4.0/

\begin{abstract}
Mayer-Rokitansky-Kuster-Hauser Syndrome (MRKH) is a rare disease characterized by total or partial vagina agenesis, karyotype $46, \mathrm{XX}$ with normal secondary sexual characters. Still, it is the second leading cause of primary amenorrhea. The absence of obvious signs and symptoms often causes the syndrome to be diagnosed only after puberty. The case presented here highlights exactly this difficulty of early diagnosis, which meets the objective of the study, and is precisely to provide reliable material that facilitates the diagnosis and management of patients with MRKH syndrome.
\end{abstract}

\section{Keywords}

Mayer-Rokitansky-Kuster-Hauser Syndrome, Primary Amenorrhea, Gonadal Dysgenesis

\section{Introduction}

Mayer-Rokitansky-Küster-Hauser syndrome (MRKH) is a congenital Mullerian dysgenesis that develops with vagina atresia and uterine and tubal anomalies and may present with absence or hypoplasia of these structures [1] [2] [3] [4]. In these cases, the patients present 46, XX karyotype with preserved secondary sexual characters, as the ovaries are normally functioning [2]. A rare disease, considered the second most frequent cause of primary amenorrhea, affects 1:5,000 live-born girls [1] [2] [3]. 
The etiology has not yet been fully clarified; however, it is believed to be related to a genetic cause due to the increase in the number of cases in family groups [2] [3]; thus, the existence of an autosomal dominant inheritance has been suggested [1] [5]. Although the exact genetic cause has not been discovered, genes such as HOXA7, HOXA 9-13, HOXD 9-13, and WNT4 are considered as possible causes of the syndrome [3] [4]. Errors in embryological development are likely to occur from the fourth week of gestation, which would culminate in the regression of the Muller ducts [1]. Additionally, although there are also suspicions of non-genetic causes, there is no relationship with the use of illicit drugs during pregnancy [3].

MRKH syndrome is classified into 3 types according to the involvement of the reproductive system alone or, simultaneously, to changes in other structures. The classifications are as follows: type I or typical, in which malformations are restricted to the reproductive system; type II or atypical, with genital malformations associated with extragenitals, such as renal, congenital otologic, bone, and ovarian diseases [2] [3]. A third type, MURCS (Mullerian Renal Cervical Somite), presents with uterovaginal, bone, renal, and cardiac alterations [2] [3].

The diagnosis at birth is exceptional; however, it is usually made during adolescence [5]. Between the ages of 14 - 16 years old, patients seek medical attention complaining of menarche and/or dyspareunia, whether or not accompanied by cyclic colic [3]. Associated with amenorrhea, agenesis justifies the sterility and impossibility of vaginal intercourse, related to psychosocial problems such as depression, low self-esteem, and personality changes [2] [3] [4] [6].

Three methods of confirmation of MRKH syndrome are used: ultrasound (US), magnetic resonance imaging (MRI), or laparoscopy. The association of US with clinical examination has been reported to be as effective as MRI alone at diagnosis [7]. However, MRI has advantages beyond US, such as the ability to obtain multi-planar imaging, better visualization of renal anomalies, the possibility of diagnosing extragenital anomalies such as skeletal and cardiac abnormalities, and providing greater data when the chosen treatment is surgical [8] [9] [10].

Treatment may be conservative or surgical depending on the degree of agenesis and patient choice together with a multidisciplinary team [7] [8] [9] [10].

The aim of the study is to present a case report of a patient in order to provide more theoretical material for studies, facilitating the early diagnosis, and treatment of these women.

\section{Case Report}

The patient has given the consent for the case report to be published.

Patient, 21 years old, black, female phenotype, virgin, unemployed, sought health service reporting never having had a menarche, being referred to the endocrinology ambulatory.

Physical examination revealed: weight $91.5 \mathrm{~kg}$, height $1.60 \mathrm{~m}$, atypical face, severe hirsutism (Ferriman and Galway scale 14), cervical and axillary acanthosis 
nigricans, absence of hearing impairment, secondary sexual characteristics developed according to chronological age-Tanner M4 G4.

Performed progesterone + estrogen test to assess vaginal bleeding after stimulation and direct investigation. With negative result, the hypothesis of anatomical alteration as a cause of amenorrhea is reinforced.

The complementary exams showed: estradiol $85 \mathrm{pg} / \mathrm{ml} ; 17-\mathrm{OH}$-progesterone $226.9 \mathrm{ng} / \mathrm{dL}$; FSH $3.1 \mathrm{mIU} / \mathrm{ml}$; prolactin $13.4 \mathrm{ng} / \mathrm{ml}$; testosterone $42.2 \mathrm{pg} / \mathrm{ml}$; TSH $3.2 \mu \mathrm{IU} / \mathrm{ml}$, justifying secondary sexual characteristics.

Pelvic ultrasound did not visualize the uterus between the bladder and the rectum. Gynecological evaluation requested: breast examination without changes to superficial and deep palpation; only $1 / 3$ inferior of the vagina confirmed with rectal touch. No specular examination was performed.

MRI of the abdomen and pelvis showed uterine and vaginal agenesis, as shown in Figure 1.

In the genetic study the result was karyotype $46, \mathrm{XX}$.

Based on these results, the association of primary amenorrhea, absence of the upper 2/3 of the vagina at MRI and genetic examination showing karyotype 46, $\mathrm{XX}$ the conclusive diagnosis is Mayer-Rokitansky-Küster-Hauser syndrome.

The treatment chosen by the team of gynecology and the patient was surgical correction with the creation of a neovagina. At the present moment, the patient is still waiting for the consultation by the public health with obstetric surgery specialist.

\section{Discussion}

MRKH syndrome occurs due to the embryological alteration of the Mullerian ducts-formed between the eighth and twelfth weeks of gestation-which will

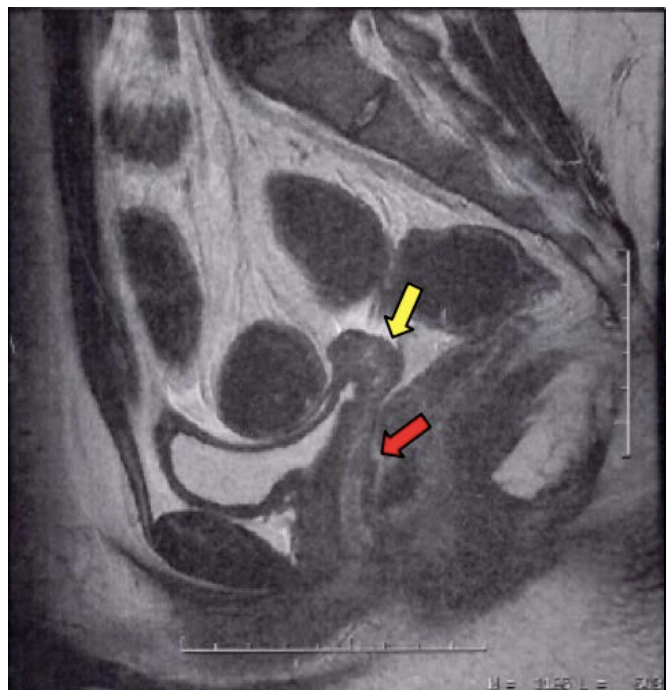

(a)

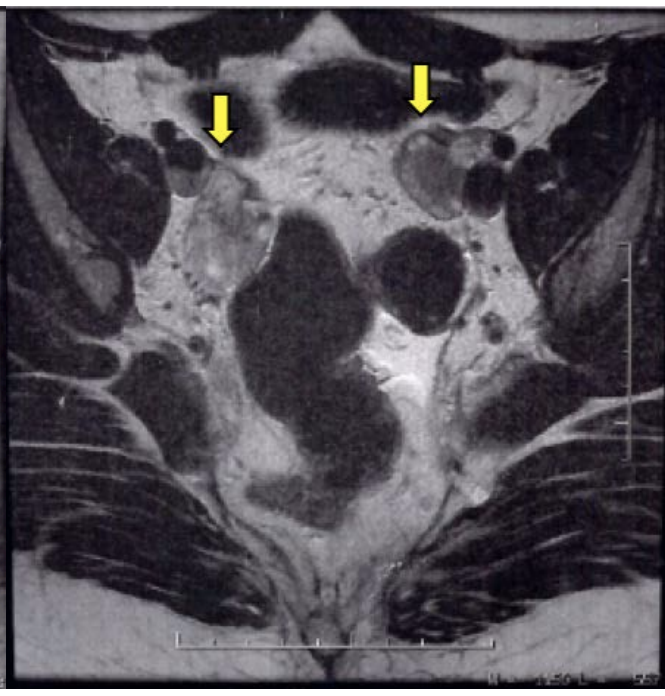

(b)

Figure 1. MRI images, sagittal section (a) shows the uterine store (yellow arrow) and the lower third of the vagina (red arrow), and the axial section (b) shows the presence of the ovaries (yellow arrows). 
lead to agenesis or hypoplasia of the uterus and upper third of the vaginal canal [4]. An association between Mullerian duct malformation with gestational diabetes and thalidomide use during pregnancy has been reported [1].

Most patients are diagnosed late in adolescence or adulthood when complaints of dyspareunia or absence of menarche appear [3] [11]. Unfortunately, in the case of the patient above, the diagnosis was even later, since the absence of menarche until the age of 15 with the presence of secondary sexual characters should be investigated as to the causes of primary amenorrhea.

The clinical presentation consists of primary amenorrhea with preserved sexual characteristics, compatible with age [2] [4] and preserved external genitalia [12]. The occurrence of colic may or may not be present [2] [4].

MRKH syndrome has numerous variables regarding the presence of certain abnormalities such as: 1) renal-agenesis or hypoplasia, hydronephrosis, and ectopic kidney; 2) bone-fusion of cervical vertebrae and scoliosis; 3) cardiac; and 4) digitalis-polydactyly and syndactyly [2] [4] [13]. When present, renal and bone changes are the most frequent, with $30 \%-40 \%$ and $10 \%$, respectively, and should always be investigated at diagnosis [4].

Physical examination is the first solid evidence of alterations in the Mullerian duct, since gynecological evaluation can detect absence or shortening of the vagina canal [2] [13] [14]. In the investigative sequence, abdominal and pelvic ultrasounds are requested, which confirms the absence of uterus between the bladder and rectum [2] [14].

In addition, it is useful in assessing renal anomalies [2]. Magnetic resonance imaging is a diagnostic alternative, since it is an examination with greater accuracy and sensitivity in the internal morphological visualization, moreover, facilitating the indication and preparation for surgical correction, when indicated [1] [2] [4] [15], furthermore being the most indicated method for diagnosis [12] [16]. To conclude the diagnose, it is essential to associate the clinical spectrum of primary amenorrhea, especially after stimulating tests, with varied laboratory tests, depending on the involvement of uterine appendages, imaging tests compatible with total or partial uterine agenesis associated with karyotype $46, \mathrm{XX}$, excluding other genetic syndromes [1] [2] [4].

The patient above presented all the criteria for the diagnosis of MRKH syndrome, with evidence of vaginal and uterine agenesis, amenorrhea and karyotype 46, XX, without evidence of extragenital anomalies, being classified as type I syndrome.

The syndrome causes quality of life damages, since it arouses anxiety and psychological changes in the patient [1] [2] [3] [4]. In addition to that, appropriate multidisciplinary follow-up and treatment are required [2]. As an initial form of treatment, a dilator may be used, but it is most commonly used in women with a vaginal canal of at least $3-4 \mathrm{~cm}$ and should be used for at least 12 months to achieve a functional vagina. The dilator is the initial therapy in older women or those who do not want surgery [16]. This does not always yield results, besides 
could be a psychologically traumatic procedure and possible complications exists, as urethritis, cystitis, fistulas and secondary prolapse [5].

As a definitive method, we choose the surgical techniques indicated for the creation of neovagina, allowing patients to have an active sex life [2] [4] [7]. Patients who wish to have children should be counseled regarding the possibility of adoption or assisted reproduction [2] [4].

After been extensively discussed the options between the patient and the gynecology team, she opted for surgical treatment, according to most of the reviewed studies [2] [3] [5] [6] [7] [10] [17]. Having been referred to specialized service, the surgical treatment is indicated when the patient is emotionally mature and desires to initiate sexual relationships. Up to date there is no consensus about the best surgical technique to create a neovagina and there is no superiority method when compared sexual satisfaction and functional outcomes [5]. The laparoscopic-assisted methods create a neovagina by minimal invasive procedure [3]. While waiting for surgery, she maintained visits to endocrinology ambulatory to correct hormonal disorders, hirsutism, and obesity.

\section{Conclusions}

The psychological aspects of MRKH syndrome should never be omitted, and patient and family should be supported as a key role to perform wellbeing to these patients.

This syndrome is still rare and poorly diagnosed, and has been associated to legal, social and ethical concerns requiring a multi-disciplinary approach, and further studies to clarify the possible causes, as well as further dissemination about it, facilitating early diagnosis and appropriate treatment, thus minimizing possible psychosocial, endocrinological, and/or gynecological sequelae to patients and families, in addition to genetic counseling.

\section{Conflicts of Interest}

The authors declare no conflicts of interest regarding the publication of this paper.

\section{References}

[1] Borges, M., Pires, M., Monteiro, D. and Santos, S. (2012) Forma atípica da síndrome de Mayer-Rokitansky Kuster-Hauser com malformação renal e displasia cervicotorácica (associação de MURCS). Revista Brasileira de Ginecologia e Obstetricia, 34, 133-138. https://doi.org/10.1590/S0100-72032012000300008

[2] Gutsche, R., Chagas, L., Leal, R., Cunha, A. and Djahjah, M. (2011) Síndrome de Mayer-Rokitansky-Kuster-Hauser: Relato de caso e revisão da literatura. Radiologia Brasileira, 44, 192-194. https://doi.org/10.1590/S0100-39842011000300014

[3] Choussein, S., Nasioudis, D., Schizas, D. and Economopoulos, K.P. (2017) Mullerian Dysgenesis: A Critical Review of the Literature. Archives of Gynecology and Obstetrics, 295, 1269-1381. https://doi.org/10.1007/s00404-017-4372-2

[4] Sem, K.K. and Kapoor, A. (2006) Mayer-Rokitansky-Kuster-Hauser Syndrome. Indian Journal of Radiology and Imaging, 16, 805-807. 
https://doi.org/10.4103/0971-3026.32353

[5] Wagner, A., Brucker, S., Ueding, E.G., Gröber-Grätz, D., Simoes, E., Rall, K., et al. (2016) Treatment Management during the Adolescent Transition Period of Girls and Young Women with Mayer-Rokitansky-Küster-Hauser Syndrome (MRKHS): A Systematic Literature Review. Orphanet Journal of Rare Diseases, 11, 152. https://doi.org/10.1186/s13023-016-0536-6

[6] Escobar, D., Gryngarten, M., del Rey, G., Boulgourdjian, E., Keselman, A. and Martínez, A., et al. (2007) Síndrome de Rokitansky (agenesia úterovaginal): Aspectos clínicos, diagnósticos y terapéuticos. Archivos Argentinos de Pediatria, 105, 25-31.

[7] Govindarajan, M., Rajan, R.S., Kalyanpur, A. and Ravikumar (2008) Magnetic Resonance Imaging Diagnosis of Mayer-Rokitansky-Kuster-Hauser Syndrome. Journal of Human Reproductive Sciences, 1, 83-85.

https://doi.org/10.4103/0974-1208.44117

[8] Lermann, J., Mueller, A., Wiesinger, E., et al. (2011) Comparison of Different Diagnostic Procedures for the Staging of Malformations Associated with Mayer-Rokitansky-Kuster-Hauser Syndrome. Fertility and Sterility, 96, 156-159. https://doi.org/10.1016/j.fertnstert.2011.04.051

[9] Yoo, R.E., Cho, J.Y., Kim, S.Y. and Kim, S.H. (2013) Magnetic Resonance Evaluation of Mullerian Remnants in Mayer-Rokitansky-Kuster-Hauser Syndrome. Korean Journal of Radiology, 14, 233-239. https://doi.org/10.3348/kjr.2013.14.2.233

[10] Bombard II, D.S. and Mousa, S.A. (2014) Mayer-Rokitansky-Kuster-Hauser Syndrome: Complications, Diagnosis and Possible Treatment Options: A Review. Gynecological Endocrinology, 30, 618-623. https://doi.org/10.3109/09513590.2014.927855

[11] Lo Iudice, G., Federico, P., Pasquali, D., Petrenga, E., Schilliro, F., D’Alessandro, B. and The MURCS Association (1986) Clinical, Radiological, Endocrinological and Familial Data in a 40-Year Old Patient. Minerva Endocrinologica, 11, 205-209.

[12] Cunha, G., Alencastro, J., Ferreira, M., Alves, C. and Silveira, P. (2006) Neovagina por Videolaparoscopia na Síndrome de Mayer-Rokitansky-Kuster-Hauser. Revista Brasileira de Videocirurgia, 183.

[13] Sultan, C., Biason-Lauber, A. and Philibert, P. (2009) Mayer-Rokitansky-KusterHauser Syndrome: Recent Clinical and Genetic Findings. Gynecological Endocrinology, 25, 8-11. https://doi.org/10.1080/09513590802288291

[14] Steinkeler, F.A., Woodfield, C.A. and Hillstrom, M.M. (2009) Female Infertility: A Systematic Approach to Radiologic Imaging and Diagnosis. Radriographics, 29, 1353-1370. https://doi.org/10.1148/rg.295095047

[15] Manne, S., Veeraabhinav, H., Jett, M., Himabindu, Y., Donthu, K. and Badireddy, M. (2016) A Rare Case of 46, XX Gonadal Dygenesis and Mayer-Rokitansky-KusterHauser Syndrome. Journal of Human Reproductive Sciences, 9, 263-266. https://doi.org/10.4103/0974-1208.197694

[16] Inês, M.C. (2011) Síndrome de Mayer-Rokitansky-Kuster-Hauser descrição de um caso clínico. Universidade do Porto, Instituto de Ciências Biomédicas Abel Salazar.

[17] Patnaik, S.S., et al. (2014) Mayer-Rokitansky-Küster-Hauser (MRKH) Syndrome: A Historical Perspective. Gene, 555, 33-40. https://doi.org/10.1016/j.gene.2014.09.045 